Boise State University

ScholarWorks

Kinesiology Faculty Publications and Presentations

Department of Kinesiology

$3-1-2014$

Learning to Play: A "Hedgehog Concept" for

Physical Education

Tyler Johnson

Boise State University

This is an author's accepted manuscript of an article published in The Journal of Physical Education, Recreation \& Dance, 85(3), 32-38. 2014 @ Taylor \& Francis, available online at DOI: 10.1080/07303084.2014.875805 


\title{
Learning to Play: A “Hedgehog Concept” for Physical Education
}

\author{
Tyler Johnson \\ Department of Kinesiology \\ Boise State University
}

\begin{abstract}
What is physical education and why does it exist? Despite its relatively long and storied history, consensus about physical education's existence remains minimal. According to Jim Collins, author of the best-selling book Good to Great, organizations or groups of professionals should determine a "hedgehog concept" or a primary reason for their existence. This article explores three questions developed by Collins to help organizations identify a hedgehog concept: (a) what are we deeply passionate about? (b) what can we be the best in the world at? and/or what can we not be the best in the world at? and (c) what drives our resource engine? By drawing on ideas from physical education scholars to answer the questions, I conclude that providing a large quantity of quality opportunities for students to learn to play is a legitimate hedgehog concept for physical education. I encourage other physical education professionals to determine and disseminate answers to the three questions and identify a physical education hedgehog concept in future publications.
\end{abstract}

Keywords: physical education, philosophy, purpose

The field of physical education has long been plagued with a lack of professional focus (Hawkins, 2008; Kretchmar 2008). Kretchmar has likened physical education to a chameleon:

Chameleons, as we all know, change color and other characteristics to enhance survival. We do too. We chase one "hot topic" after another. If someone wants us to become intellectuals, we become intellectuals. If someone needs a fix for the obesity epidemic, we raise our collective hands and say, "count us in." If a couple of research studies show that activity enhances cognitive functioning, we jump on board. If anyone is looking for help with cancer, diabetes, depression, high blood pressure, wayward kids who get into trouble after school, we are among the first to volunteer. (p. 5)

Pangrazi (2010) has argued "change is important but too much change in a short time frame leads both professionals and the public to pose the questions, 'what exactly is physical education and what does it offer to students?'” (p. 325). Pangrazi continues by observing:

Our professional organizations have changed focus every five to 10 years. Some change is needed, but when it occurs in such a short time frame, teachers rarely have the opportunity to establish respect among administrators, students, and parents. Accomplishment in any field takes many years of determined and dedicated effort. Each time a new focus arises, it creates a new learning curve and teachers have to start over. (p. 326)

There is no doubt that physical education is many things to many people. If physical education teachers were to be asked “what does a physical education teacher do?” any of the following responses may be heard:

Response \#1 - "I help students improve their motor and/or sport skills."

Response \#2 - "I help students increase their knowledge of movement."

Response \#3 - "I teach students to live an active, healthy lifestyle.”

Response \#4 - "I motivate students to improve their physical fitness.”

Response \#5 - "I help students build social skills."

Response \#6 - "I teach kids to value physical activity." 
A physical education teacher can respond using any or all of these reasons and be correct. These responses should sound very familiar especially to those who know the national content standards (National Association of Sport and Physical Education [NASPE], 2010).

The very existence of these standards, in some respects, has continued to perpetuate segregation and confusion in the field. Some argue our most important responsibility is the teaching of motor or sport skills (Stodden, Goodway, Langendorfer, Roberton, Rudisill, \& Garcia, 2008); others argue that we need to focus on the science behind movement to earn some academic respect (Corbin \& Lindsey, 2005); and in perhaps the most popular view today, others argue for the public health approach to physical education (Pate, O’Neill, \& McIver, 2011; Sallis, McKenzie, Beets, Beighle, Erwin, \& Lee, 2012). The point is there are multiple platforms competing for our time and attention. To make matters worse we all know students spend a limited amount of time, oftentimes much less than recommended, receiving physical education instruction (NASPE, 2008). This begs an interesting but troubling question: Can we adequately help students achieve satisfactory performance in each standard with the time we have available?” Such an expectation seems beyond reason or possibility. Kretchmar (2005) has argued we desperately need to "prioritize" and determine which of the aforementioned areas of focus is most important to us. If we fail to prioritize we risk spreading our professional focus so thin that we end up accomplishing very little in return.

In his best-selling book Good to Great, Collins (2001) delineates a key ingredient to success for any organization or group of professionals he calls the "hedgehog concept." A hedgehog is a small mammal with spiny hollow hairs made of keratin, a substance that makes the hairs hard and rigid. Upon encountering a predator, like a fox, a hedgehog can defend and/or protect itself by rolling into a tiny ball so its spiny hairs get even more rigid and sharp. The hedgehog does not need multiple strategies or tactics to defend itself. It has one characteristic strategy that is easy to employ and effective. Collins argues that organizations or groups of professionals need a defining, characteristic strategy — one main area of expertise or identity - to build a successful enterprise. According to Collins, organizations or groups of professionals that develop a clearly defined hedgehog concept are significantly more likely to achieve long-term success compared to those who do not. Furthermore, Collins argues the identification of a hedgehog concept is critical for organizations in both the corporate arena and social sectors (Collins, n.d.).

To determine a hedgehog concept, according to Collins, an organization should clearly answer the following three questions: (a) What are we deeply passionate about?; (b) What can we be the best in the world at and/or what can we not be the best in the world at?; and (c) What drives our resource engine? The hedgehog concept emerges from answers to these three questions. For the field of physical education, answering these questions can serve as a valuable exercise that may help us better understand our primary purpose. Notice that purpose is singular and not plural. If we continue to define multiple purposes for our existence we will continue to be a fragmented group of professionals. The ultimate question we are answering by determining a hedgehog concept is "why do we exist”? If we can pinpoint and consistently support a primary reason for our existence-our hedgehog concept or brand —it is likely we can elevate the value of physical education in educational institutions.

The purpose of this article is to answer the three questions by drawing on ideas from various physical education scholars with the intent to identify a hedgehog concept for physical education.

\section{Hedgehog Concept Question \#1 - What are we deeply passionate about?}

Physical education professionals probably value many, if not all, of the purposes of physical education delineated in the national content standards. We value these purposes because each of us has likely experienced them via involvement in aquatics, dance, exercise, games, outdoor recreation, or sport activities. We also gravitate to these purposes because they are easy to describe and understand. Unfortunately, we oftentimes hastily conclude, with little thought and insight, that skills, knowledge, and activity/fitness are what we deeply value. I believe this is a mistake.

What we probably value at a much deeper level is how the attributes of skill, knowledge, and fitness allow us and our students to more fully enjoy and derive greater satisfaction and meaning from playing and/or participating in movement-related activity. Hawkins (2008) observes "I would assert, that for most us, the reason we decided to go into an undergraduate physical education program was a deep-seated love for the subject matter in and of itself" [italics added] (p. 354). To some degree we probably chose this profession because we had a "deep-seated love” for 
This is an author's accepted manuscript of an article published in The Journal of Physical Education, Recreation \& Dance, 85(3), 32-38. 2014 (c) Taylor \& Francis, available online at DOI: 10.1080/07303084.2014.875805

active engagement in movement-related activity. Our participation in such activities has and probably still does play a significant role in our development as human beings. Eleanor Metheny (1965) insightfully declared many years ago to physical educators:

We play tennis [or any other movement-related activity] for the same reason that [people] paint pictures, sing, play musical instruments, devise and solve algebraic equations, and fly airplanes. We play tennis because it satisfies our human need to use our human abilities, to experience ourselves as significant, creative, and therefore, personalized beings in an impersonal world. We do these things to intensify, structure, and enhance the sensory perceptions that are our only direct source of information about ourselves and the world we live in, and these sensory perceptions are the source of the human meanings we find in our human lives [italics added]. (p. 104)

Our identities as human beings are intricately tied to our involvement in movement-related activities. We are known as golfers, swimmers, powerlifters, skaters, skydivers, hikers, mountain bikers, skiers, and so on. We are players of all kinds of activities. We work on golf skills so we can use those skills when we actually play a round of golf. We increase our knowledge of batting mechanics so we can hit the ball better during future at-bats. We improve our aerobic endurance so we can play a soccer game without experiencing undue fatigue. Generally speaking, we do not improve skill, knowledge, or fitness as ends in themselves. We pursue them to help us derive greater satisfaction, delight, and pleasure while actually playing. Hawkins (2008) has poignantly stated, using Michael Polanyi's theory of meaning, the danger of focusing on skills, knowledge, and health/fitness outside the context of their intended purpose:

...our profession is, in essence, taking the subsidiaries of our subject matter [i.e., skill development, knowledge, fitness, and health] and making them the object of our focal attention. The result is the loss of meaning. [Why should we develop skills?] Why should we be healthy? Why should we develop strength and endurance? We should be [skilled], healthy and strong, and have endurance to do something else. [Skill development], health and wellness are subsidiaries which only have meaning as they bear on the purpose for which they are employed [italics added]. (p. 352)

Without a meaningful milieu to use skills, knowledge, or fitness, practice and/or training to improve these attributes has little purpose or value. The doing or playing of activities must always be the foundation of our profession. Rintala (2009) declared "fitness and skill are not ends in themselves but the means to the autotelic activities of playing, gaming, dancing, sporting, and exercising (p. 286). Siedentop (1980) alleged:

Like art and music, physical education activities can be used to reach other goals, but this does not mean that they should so be used in school programs of physical education. And there is always the danger that in using the activities for other purposes, a person might never come to know what we know - the joy, frustration, and wholeness of being a player [italics added] (p. 260).

Although our interests as physical education professionals likely span various activities, our involvement playing or participating in these activities has been a significant source of meaning in our lives-something we are deeply passionate about.

I argue also that we are deeply passionate about helping students develop meaning in activity. Teachers commonly measure success by the level of student engagement with the subject matter-the higher the level of engagement the more students learn and the more teachers feel successful. Physical education teachers witness higher levels of engagement when students get "lost in play" or enter a "second world" where all other concerns vanish (Blankenship \& Ayers, 2010). For teachers the best moments are when it is obvious students have forgotten about all other concerns and are fully involved in an activity. We love these moments because we know they have the potential to teach students more about physical education content and themselves than we could ever teach; such moments are filled with habit forming feelings, desires, and meanings that are more likely to entice students to continue participation well into the future. 
The "power of playing" in all its various forms is undeniable and unforgettable. In large part, we chose to become physical education professionals because we want to help young people experience play like we have experienced play. The answer to question \#1 is quite clear-we are deeply passionate about the doing or playing of activity, both for ourselves and for our students.

\section{Hedge Hog Concept Question \#2 - What can we not be the best in the world at? and What can we be the best in the world at?}

What can we not be the best in the world at? Pangrazi (2010) argues physical education professionals have for many years "chased [the] unachievable outcomes" of physical fitness and motor skill development. First, he declares genetics determines to a large extent how students physiologically respond to fitness training. Even with consistent training some students can show significant improvement while others do not. Moreover, most preadolescent youth show very little response to training. He continues:

Unfortunately, such genetic limitations are often ignored and most physical education professionals believe that all people can improve their fitness level if they train diligently. This misconception results in unrealistic expectations for many teachers and students while administrators and the public view it as evidence teachers are failing. (p. 326)

Is it fair to measure fitness levels when what we do in physical education has little to do with how students perform on fitness tests?

In conjunction with this argument, what is the likelihood that our current efforts to "get kids fit" will remedy the childhood obesity or non-infectious disease epidemics when our efforts to "get kids fit" during the 1950s, 60s, and 70s did not prevent these epidemics from happening in the first place? The high sense of urgency and commitment to improve the physical fitness levels of American children and youth after the Kraus-Weber test was probably comparable to our sense of urgency and commitment today to get kids fit. Their efforts were not successful then; hence, what makes us believe our efforts today will be any different?

Second, Pangrazi (2010) argues motor skill development is not an appropriate outcome because "skill performance is also genetically controlled ... and often favors the genetically gifted and discourages those less fortunate" (p. 327). He also asserts that the validity and reliability of motor skill assessments remain tenuous, and that skill assessment or testing is time-consuming extracting precious time for actual skill learning.

Most teachers learn very quickly that they cannot force kids to get fit or to learn skills. Students will not do so until they perceive it as meaningful for some other purpose. As Metheny (1965) declared:

Just 'going through meaningless motions' does not produce physical fitness [or skill development]. Fitness [and skill development] comes from continuing to move past the point of mild fatigue. It was only because those movements were meaningful to us that we continued to hit tennis balls while the perspiration poured from our skins, went on walking after golf balls while our legs ached, and continued leaping and falling in the dance studios until we were so tired we could scarcely walk ... physical fitness and [skill development] resulted from our meaningful perseverance [italics added] (p. 106).

Too much of physical education today may be "going through meaningless motions" where students see little value in the activities. Perhaps our preoccupation with fitness and skill in many ways repels students because it purloins the inherent playful nature out of physical education content.

We cannot hang our professional hats on physical fitness or motor skill development and expect to be successful. We cannot guarantee kids will get fit or skilled as a result of physical education any more than parents can guarantee their child will be a professional athlete. As Pangrazi (2010) argues, we should cease "chasing [these] unachievable outcomes."

So, what can we be the best in the world at? Metheny (1965) declared to a group of physical education professionals: 
Our primary job as physical educators is to provide opportunities for children to move in many ways and for many reasons so that they may find some of the many satisfactions and meanings that we have found in our own sensory experiences of human movement. Our educational significance rests on our ability to provide challenging and satisfying movement experiences [italics added]. (p. 105)

Metheny's invitation here is twofold: (a) provide many opportunities for young people to move and (b) "provide challenging and satisfying movement experiences." In other words, we are responsible for offering a large quantity of quality opportunities for children and youth to experience movement.

Some students can be learners of activity(s) and/or sport(s) on their own with little assistance from a teacher. Generally speaking, these are students who are endowed with kinesthetic intelligence (Gardner, 1993). We need to respect such students' instinctive ability to create "satisfying movement experiences" on their own. Providing opportunities for them to participate is oftentimes all that is needed. Other students require, however, more structure, guidance, and encouragement to experience and enjoy an activity/sport. These may be students who, for various reasons, feel uncomfortable in such domains. They need or perhaps long for teacher leadership or sometimes the leadership of a worthy peer to help them decide to invest themselves in an activity and/or sport. Such students should not be expected to navigate their way to blissful experiences with an activity and/or sport on their own. They deserve a path paved with appropriate movement modifications.

\section{Quantity of Opportunities}

Approximately 55 million children and adolescents living in the U.S. attend public or private schools where they spend roughly 40 hours per week (National Center for Education Statistics). No other organization or group of professionals anywhere has access to so many children and adolescents for so much time than do teachers. Schools and physical education teachers should accept these contextual factors and ensure that a large quantity of activity experiences be provided to students. For this reason, Castelli and Beighle (2007) have proposed to expand the role of a physical education teacher to that of a Director of Physical Activity (DPA). As a DPA, a physical education teacher assumes responsibility for creating an activity committee composed of other teachers, students, parents, and community members to plan, organize, and administer multiple opportunities for activity experiences before, during, and after school. Under this model, it makes sense that we can be the best in the world at providing the largest quantity of opportunities for students to engage in movement-related activity.

\section{Quality of Opportunities}

Physical education teachers must also be concerned with the quality of movement opportunities. Kretchmar (2005) has identified that simply "having fun" in movement activities is not as durable as experiencing delight, joy, or satisfaction. These latter sensations or emotions contain greater potential for building commitment to movementrelated activity than fun alone. Other scholars have described these sensations as "skill thrill," "flow," or "getting in the zone" (Csikszentmihalyi, 1990; Rintala, 2009). To facilitate these types of experiences, physical education teachers are responsible for ensuring movement-related content is modified to meet the developmental needs of students regardless of gender, age, or grade level. Lieberman and Houston-Wilson (2002) suggest modifications in four different areas - equipment, rules, environment, and instruction - to create optimal or "just right" activity/sport challenges (Blankenship \& Ayers, 2010). Any activity/sport can be appropriately altered using any combination of these modifications. Students are more likely to have positive experiences in an activity/sport when they feel successful and competent (Bryan \& Solmon, 2007).

The answer to hedgehog question \#2 is we can be the best in the world at providing the largest quantity of quality opportunities for students to engage in activity.

\section{Hedge Hog Concept Question \#3 - What drives our resource engine?}

Collins (2001) identifies the three primary resources needed by organizations in the social sector: money, people, and brand. Money is surely needed for a variety of reasons in physical education (e.g., purchasing equipment and supplies, hiring support staff, etc.). Physical education professionals often report, however, that monies for these 
purposes are rarely if ever sufficient to satisfy program needs. We surely need monetary resources to support our programs, and strategies to secure funding via grants, fundraisers, and donations can and should be pursued. I argue, however, our most important resource is not money.

Physical education is a service rather than a product. Our service is the planning, organizing, delivering, and evaluating of physical education content for and in behalf of students. Teachers are not, however, solely responsible for a successful service transaction. Physical education requires significant commitment from students as well as teachers for the service to be successful. If one of the two parties is not committed, the service will be ineffective. For this reason our greatest resource will always be students! We desperately need their youthful enthusiasm, passion, and zeal to make physical education meaningful and productive and perhaps more valued in educational institutions. Without their emotional investment, all our efforts to provide a quality service will be for naught. So, the real question is what drives or motivates young people in movement-related settings?

Physical education, of all subject matters, may have the greatest draw for students because the content is inherently playful - the prospect of play attracts students to physical education. In too many cases, however, we do more to stifle than build student enthusiasm by expecting all students to learn content they are not ready to learn, participate in activities unrelated to their interests, and follow unnecessary rules and policies. In other words, we plug our content into the rigid structure of education with multiple standards, objectives, and time requirements and in too many cases end up robbing the content of its inherent playful nature. I believe it is time to strongly reconsider how we package and present physical education content to students to allow the content to do what it is capable of doing on its own-to "attract," "draw in," and "hook" students. To best utilize our greatest resource-students—-we need to allow the inherent playfulness of our content to have full sway in physical education. Kretchmar (2006) poignantly observes "if we cannot get more than 80 percent of our students to say that physical education is absolutely the best part of the school day then we are probably squandering our [content] (p. 7).

Perhaps today more than ever students are bombarded with the message that movement or physical activity is something they should do rather than get to do. Is it any wonder some students view physical education and/or movement-related activity as "work" more than "play" (Stoll et al., 2000) or as "going through meaningless motions" (Metheny, 1965)? Students are more likely to lose interest when activity is pursued as a means to an end rather than an end in itself (Deci \& Ryan, 2000). For this reason intrinsic interest should be a guiding principle for physical education.

Why should an adolescent female be required to learn flag football or soccer when she finds yoga and aerobics more interesting? Why should an eight-year-old boy be expected to run laps around the soccer field when playing basketball is more appealing? These are good questions to ask. A common argument is that students do not get to choose what they learn or do in math or science class, so why should they be allowed to choose what they learn or do in physical education. I believe such thinking harms our subject matter. This is physical education! It is not math or science or history. The moment we try to be like other subject matters is the moment we forfeit the nature of our subject matter. Students deserve, especially in schools, intrinsically interesting activities and it is our job to provide opportunities for them to pursue these interests.

There may not be a more important message for physical education professionals: our strength as a profession lies in the intrinsic value of our subject matter. Accordingly, the answer to hedgehog question \#3 is we drive or motivate our greatest resource-students—by accepting, valuing, and promoting the intrinsic value of movement.

\section{Learning to Play: A Hedgehog Concept for Physical Education}

This article has provided answers to three questions with the intent to identify a hedgehog concept for physical education. By merging these answers (see Figure 1), I conclude that providing a large quantity of quality opportunities to learn to play is a valid hedgehog concept for physical education - a concept we can consistently support, promote, and brand. Play has and always will be a fundamental part of human existence and therefore will not change with the times (Kretchmar, 2005).

Some might claim that we do not need to teach children and youth how to play because they already know how. As Guedes (2007) declared "to teach a child how to play is akin to teaching a priest how to pray" (p. 31). Siedentop (1980) offers a strong rebuttal to such reasoning: 
An active and productive play life is something that is learned. It is not developed by chance, nor is it in its specific forms attributable to inherited traits. Physical education is one of those agencies that society uses to initiate its younger members into culturally important forms of motor play [italics added] (p. 262).

May I add that "physical education” does not just occur in a formal physical education class but in and through a multiplicity of opportunities for children and youth to engage in activities of interest (e.g., pick-up games, recess, intramurals, physical education, etc.). Providing a large quantity of quality opportunities for students to learn to play is a viable way to assist students in developing an "active and productive play life," something they can take with them into adulthood.

Action Items: “I am a PE Teacher. What Do I Do Now?”

I propose three action items for physical education teachers to successfully implement the hedgehog concept identified in this article.

1. Increase the number of opportunities for students to engage in activities of interest while on school premises. This suggestion corresponds with recent national trends. For example, the Let's Move! Active Schools initiative recently launched by First Lady Michelle Obama (www.letsmoveschools.org) calls on physical education teachers and other school personnel to increase opportunities for students to be active before, during, and after school. In line with a hedgehog concept rooted in "play," I argue that opportunities to be active must correspond to student interests. For example, perhaps an activity/sport interest survey can be administered to students before program implementation so activity/sport preferences can be identified and appropriate opportunities organized to meet the developmental aspirations and needs of students.

2. Assume responsibility for building "play communities" in school settings. A promising way to assist students in learning to play is via specific activity/sport "play communities" (Kretchmar, 2000; Stoll et al., 2000). A play community is a group of people (large or small) who meet together often to participate in a specific activity/sport. For example, an "Ultimate play community" might be a group of students who attend school a half hour early each Tuesday and Thursday to play Ultimate or a group of teachers who play volleyball Mondays after school. Play communities can be successfully established during physical education class time too. Due to the abundance of possible activity/sports, a physical education teacher must delegate responsibility to students, other faculty/staff, parents, or other adult volunteers to help establish and maintain a variety of play communities (Kretchmar, 2000). Participants who already possess some enthusiasm, skill, and knowledge of an activity/sport can be assigned to mentor those who are new to the activity. It is by way of regular and persistent involvement with a play community that a person develops into a "player" of the activity/sport. Consider the following example:

Ramon, a high school student, was introduced by his physical education teacher to a group of high school Ultimate players who meet at the school each Tuesday and Thursday afternoon to play. After watching them play, Ramon decided to try the sport. Although he possessed minimal skill and knowledge of the game when he started, he is now, two years later, a full-blooded member of the Ultimate "play community" in his city. He plays pick-up and league play games two to three times per week. He has even started running and lifting weights to improve his aerobic and anaerobic fitness to play the sport. When asked recently why he loves the sport he declared "I feel most like myself on a Frisbee field" [italics added].

It is important to note that the physical educator must ensure the activities and/or methods of each play community are developmentally appropriate for the age, maturity, and experience level of students. 
3. Share decision-making with students. Students need more control over their own learning experiences to become 'physically educated.' Mosston and Ashworth's (2002) Spectrum of Teaching Styles provides an excellent framework for teachers to share decision-making with students. The Spectrum contains 11 different teaching styles arranged on a continuum (see Figure 2). A teacher using the command style makes all the decisions about subject matter content, objectives, modes of communication, implementation and adjustment, and assessment and feedback. On the other hand, a teacher using the self-teaching method enables students to make all the decisions. I argue that a focus on "learning to play" requires teachers to become more competent in using student-centered teaching styles. Teachers must learn these other styles, practice them, and figure out how, when, and where to use them to help students feel a stronger sense of autonomy in physical education settings (Deci \& Ryan, 2000). When students can make more choices about their activities and learning experiences in physical education, motivation and emotional investment increase substantially (Bryan \& Solmon, 2007).

\section{Conclusion}

The hedgehog concept identified in this article offers a feasible solution to physical education's "chameleon-like" behavior. Because play is timeless, meaningful, and fundamentally human, physical education professionals should guide students in learning to play-in becoming "players" of activities/sports they find interesting. Some might contend that a focus on "play" is not sufficiently objective to be included in today's educational system. Siedentop (1980) offers a powerful reminder that a predominant focus on the so-called measurable outcomes of physical education can be distracting to what really matters:

If any concomitant values—-physical, social, mental, or emotional—accrue from playing handball, basketball, or any other activity, they accrue mostly because the participant has played. To suggest aims and objectives which are extrinsic to the activities of physical education focuses the attention of the educator — and too often the student—on the "real world" of social, emotional, mental, and physical development. The problem with this focus is that it tends to impinge upon the play world; and by doing so, it runs the risk of alienating the player from the meaning inherent in the play activities [italics added] (p. 263).

The last thing physical education teachers want to do is hinder play because the type of meaning inherent in play has significant and long-lasting potential to entice and inspire young people to be active and healthy now and well into the future (Deci \& Ryan, 2000). For this reason, physical education professionals should fully embrace and promote learning to play as their fundamental programmatic aim. 


\section{References}

Blankenship, B.T., \& Ayers, S.F. (2010). The role of PETE in developing joy-oriented physical educators. Quest, 62, 171-183.

Bryan, C., \& Solmon, M. (2007). Self-determination in physical education: Designing class environments to promote active lifestyles. Journal of Teaching in Physical Education, 26, 260-278.

Castelli, D.M., \& Beighle, A. (2007). The physical education teacher as school activity director. Journal of Physical Education, Recreation, and Dance, 78, 25-28.

Collins, J.C. (n.d.). The hedgehog concept. Retrieved April 10, 2013 from http://www.jimcollins.com/media topics/hedgehog-concept.html\#audio=73

Collins, J.C. (2001). Good to great: Why some companies make the leap and others don't. New York: HarperCollins Publishers.

Corbin, C.B., \& Lindsey, R. (2005). Fitness for life ( $5^{\text {th }}$ ed.). Champaign, IL: Human Kinetics Publishers.

Csikszentmihalyi, M. (1990). Flow: The psychology of optimal experience. New York: Harper Perennial.

Deci, E.L., \& Ryan, R.M. (2000). The "what" and "why" of goal pursuits: Human needs and the self-determination of behavior. Psychological Inquiry, 11, 227-268.

Gardner, H. (1993). Multiple intelligences: The theory into practice. New York: HarperCollins.

Guedes, C. (2007). Physical education and physical activity: A historical perspective. Journal of Physical Education, Recreation, and Dance, 78, 31-32, 47-48.

Hawkins, A. (2008). Pragmatism, purpose, and play: Struggle for the soul of physical education. Quest, 60, 345-356.

Kretchmar, R.S. (2000). Movement subcultures: Sites for meaning. Journal of Physical Education, Recreation, and Dance, $71,19-25$.

Kretchmar, R.S. (2005). Practical philosophy of sport and physical activity ( $2^{\text {nd }}$ ed.). Champaign, IL: Human Kinetics.

Kretchmar, R.S. (2006). Ten more reasons for quality physical education. Journal of Physical Education, Recreation, and Dance, 77, 6-9.

Kretchmar, R.S. (2008). Leadership leanings. The Chronicle of Kinesiology and Physical Education in Higher Education, 19, 4-7.

Lieberman, L., \& Houston-Wilson, C. (2002). Strategies for inclusion: A handbook for physical educators. Champaign, IL: Human Kinetics.

Metheny, E. (1965). Connotations of movement in sport and dance. Dubuque, IA: WM. C. Brown Company Publishers.

Metheny, E. (1968). Movement and meaning. New York: McGraw-Hill Book Company.

Mosston, M., \& Ashworth, S. (2002). Teaching physical education. (5 ${ }^{\text {th }}$ ed.). San Francisco: Benjamin Cummings.

National Association for Sport and Physical Education. (2008). National standards and guidelines for physical education teacher education ( $3^{\text {rd }}$ ed.). Reston, VA: Author.

National Center for Education Statistics. (n.d.). Actual and projected enrollment in PK-12 elementary and secondary schools, by control of school: Fall 1995 through fall 2020. Retrieved Jan 28, 2012 from http://nces.ed.gov/programs/projections/projections2020/tables.asp

Pangrazi, R.P. (2010). Chasing unachievable outcomes. Quest, 32, 323-333.

Pate, R.R., O’Neill, J.R., McIver, K.L. (2011). Physical activity and health: Does physical education matter? Quest, 63, 19-35.

Rintala, J. (2009). It's all about the -ing. Quest, 61, 279-288.

Sallis, J. F., McKenzie, T. L., Beets, M. W., Beighle, A., Erwin, H., \& Lee, S. (2012). Physical education's role in public health: Steps forward and backward over 20 years and HOPE for the future. Research Quarterly for Exercise and Sport, 83, 125-135.

Siedentop, D. (1980). Physical education: Introductory analysis. ( $3^{\text {rd }}$ ed.). Dubuque, IA: Wm. C. Brown.

Stodden, D.F., Goodway, J.D., Langendorfer, S.J., Roberton, M.A., Rudisill, M.E., \& Garcia, C. (2008). A developmental perspective on the role of motor skill competence in physical activity: An emergent relationship. Quest, 60, 290-306.

Stoll, S., Matthews, A., Trainer, M., McGlaughlin, C., Beller, J. M., \& Matthews, J. (2000). I play, therefore I am. Journal of Physical Education, Recreation, and Dance, 71, 50-55. 